Tables de constantes et données numériques 1 : Constantes sélectionées, Longueurs d'onde des émissions $\mathrm{X}$ et des discontinuités d'absorption $\mathrm{X}$. Par Y. Cauchois et H. Hulubei. Pp. 200. (Paris : Hermann et Cie., 1947.)

GINCE the publication of Siegbahn's "Spektroskopie $\checkmark$ der Röntgenstrahlen" no authoritative list of wave-lengths of X-ray emission lines and absorption edges has been published. Cauchois and Hulubei have performed a praiseworthy task in presenting these data in one volume; they give the wave-lengths in order of increasing magnitude, values of $\nu / R$ and $\sqrt{\nu / R}$, and references to original sources. An additional table gives the values for non-diagram lines (which are probably due to transitions in multiply ionized atoms), and an appendix gives the data for each element arranged in order of atomic number.

It will be seen that the book is of interest mainly to X-ray spectroscopists, and for their convenience simple multiples of the wave-lengths are also inserted in the main table. These are described as higher orders, which means that they are the wave-lengths that would be deduced if the observed lines were taken as first-order diffractions.

The authors have chosen the results of particular researches for inclusion in their tables, rather than the means of recent determinations. It is difficult to see the justification for this, when many workers have produced results of comparable accuracy. Some discussion of the whole question of accuracy would have been valuable, since X-ray crystallographers have tended to accept data given to any number of figures. It is pleasing to note that the authors have not given any real values (that is, first orders in their notation) to more than six figures, so that, for example, CuK $\alpha$ appears as $1537 \cdot 40 \mathrm{X}$. instead of the usual $1537 \cdot 395 \mathrm{X}$.; but one would have welcomed more discussion of this question of accuracy.

\section{H. LIPSON}

\section{Experimental Embryology in the Netherlands, $1940-1945$}

By Prof. M. W. Woerdeman and Prof. Chr. P. Raven. (Monographs on the Progress of Research in Holland during the War.) Pp. xi + 132. (New York and Amsterdam : Elsevier Publishing Co., Inc., 1946.) $6.50 \mathrm{fl}$.

7 HIS small volume was prepared by Profs. 1 Woerdeman and Raven during the last months of the War, with the purpose of presenting as soon as possible an account of the work which had been done in experimental embryology during the German occupation, and which had therefore remained either unpublished or at least unknown to men of science of the Allied nations. When one considers the diff. culties under which the work must have been done, the record is a remarkable one. The group at Utrecht under Raven has made an intensive study of the egg of Limnea, a representative of the so-called 'mosaic' eggs which have been rather unfashionable experimental material in recent years. Their careful histochemical study of the process of maturation, and their description of the different plasms and their behaviour after centrifugation, may be expected to direct the attention of students of general cell physiology to the extraordinary but fascinating phenomena to be seen in the cytoplasm of egg-cells. In Woerdeman's laboratory, work has been mainly on the more classical object of the Urodele egg.
Perhaps the most striking new line of attack is that opened by experiments of ten Cate in which he has shifted the time of embryonic determination relative to that of anatomical development.

Elsevier's Encyclopædia of Organic Chemistry Edited by E. Josephy and F. Radt. Vol. 14 : Tetracyclic and Higher-Cyclic Compounds, Series 3 : Carboisocyclic Condensed Compounds. Pp. xx+711. (New York and Amsterdam: Elsevier Publishing Co., Inc., 1940.) n.p.

$\mathrm{T}^{\mathrm{T}}$ is impossible to give a critical review of what. after all, is a dictionary or catalogue.

The volume at present under consideration covers all condensed-ring hydrocarbons, sterols, bile acids, sex hormones, heart poisons and sapogenins. It is claimed that the literature is covered up to the end of 1936; but in fact the book also contains many later references, going as far as 1939. We are informed that periodical supplements are to be published, and these will doubtless bring the references up to date.

The related compounds are also found in tabular summaries or charts showing their interrelationship and methods of formation. There is an excellent formula index, as well as a very complete subject index containing even such compounds as desoxy. tetrahydroanhydrodigitoxigenin.

From the production point of view the volume is excellent; the formulæ are very clearly drawn and the text is easy to read.

The book should be of great assistance to sterol chemists, especially those who have no access to a modern edition of Beilstein. It is a convenient source of reference to a large number of organic compounds, thus saving much time spent in searching through Beilstein and numerous abstract indexes.

The present volume is No. 14, and the price of this is quoted as in the region of 60 dollars. Subscription to this series is therefore no light matter.

\section{Functions of a Complex Variable}

By Prof. Thomas M. Macrobert. Third edition. Pp. $\mathrm{xv}+390$. (London: Macmillan and Co., Ltd., 1947.) 18s. net.

T $\mathrm{T}$ will be recalled that this volume first made its 1 appearance in 1917. After a reprint in 1925, a second edition followed eight years later, and this was also reprinted in due course. It contained a considerable amount of additional subject-matter, occupying some fifty pages, mainly devoted to the study of special functions, and it is interesting to note that a reviewer at the time described it as a book in which the student would find just the material he required, clearly set out and with sufficient rigour for his needs, without delving too deeply into abstract theory.

No greater justification of this statement and no more convincing proof of the usefulness of the book to students of the theory of functions could be pro. vided than the fact that the production of yet another (the third) edition has taken place in such a short space of time. On this occasion the author has again extended the scope of the work by a further twenty pages, constituting an appendix on generalized hypergeometric functions, together with another set of miscellaneous examples. Apart from these additions, the contents are identical with those of the second edition. In spite of present-day austerity, the book is well bound and clearly printed, and it seems natural to suppose that it will continue to enjoy a well-earned popularity.
J. H. Pearce 